\title{
Techno-Economical Study of Using Nuclear Power Plants for Supporting Electrical Grid in Arabian Gulf
}

\author{
Ali M. Eltamaly ${ }^{1}$. Amer Nasr A. Elghaffar ${ }^{2}$
}

Received: 3 March 2017 / Accepted: 22 August 2017 / Published online: 1 September 2017

(c) Springer Nature Singapore Pte Ltd. 2017

\begin{abstract}
Generating electric power in Gulf region is depending on fossil fuels especially crude oil, natural gas and coal plus their derivatives. With increasing of the life standard and the world population, the fear of running out of these fuels in the long term is a great concern. So, it is better to search for reliable power in the future to be used instead of fossil fuels and also to take advantage of the energy consumed to export. Renewables like solar or wind power plants are very important to save a considerable amount of oil. But, they are not a secure option for feeding basic loads. Nuclear power Plants (NPP) are the best option to feed basic loads. Uranium is an available element in many places on earth and now feeding about 1000 reactor nuclear power around the world. This paper discusses NPP cost analysis in Gulf countries, design characteristics that represent a fundamental part of the Power Reactor Information System (PRIS), briefly describe the safety and essential auxiliary systems, and its importance for increase the security and reliability of the power system in Gulf region.
\end{abstract}

Keywords Nuclear power plant · Uranium · Renewable energy $\cdot$ Power system and safety

Ali M. Eltamaly

eltamaly@ksu.edu.sa

Amer Nasr A. Elghaffar

amernasr70@yahoo.com

1 Electrical Engineering Department, Mansoura University, Mansoura, Egypt

2 Electrical Engineering EETC and Electrical Engineering Department, Minia University, Minia, Egypt

\section{Introduction}

Gulf Cooperation Council (GCC) is a collective of six countries or nations Bahrain, Kuwait, Oman, Qatar, Saudi Arabia and UAE, which show in Fig. 1. Demand for power in GULF is increasing very fast. Renewable sources of energy, such as wind and solar power plants are important. But, there are cannot satisfy the total requirements of energy due to its intermitted nature. NPP can play an important role in this matter by feeding basic loads with very high stability and cost reduction with respect to oil or natural gas power plants. By 1900, physicists knew the atom contain large amounts of energy, British physicist Ernest Rutherford was called the father of nuclear science because of his contribution on theory of atomic structure, Albert Einstein developed his theory of the relationship between mass and energy where the mathematical formula is $E=M C 2$. The relationship between oil and nuclear energy in the global energy scene over the past 50 years is analyzed, the former nuclear, oil product competition in power generation and various end-use markets is found to have transformed into a complementary relationship "Ferenc L. Toth and Hans-Holger Rogner-2006 [1]”.

The GCC countries with their growing population require more energy for basic needs, that's depend on fossil fuel by $99 \%$. Renewable energy provides an opportunity to promote sustainable development in those regions where good renewable wind and solar resources are available and hence reduce dependence on fossil fuel-based energy. Other driving forces for utilization of renewable energy sources include vast growth in demand for electricity, increasing magnitude of carbon emissions due to burning of fossil fuels, maturing of technology, etc "S.M. Shaahid, L.M. AlHadhrami and M.K. Rahman-2013 [2]". It's very important to plan the electrical system with consideration for the load 


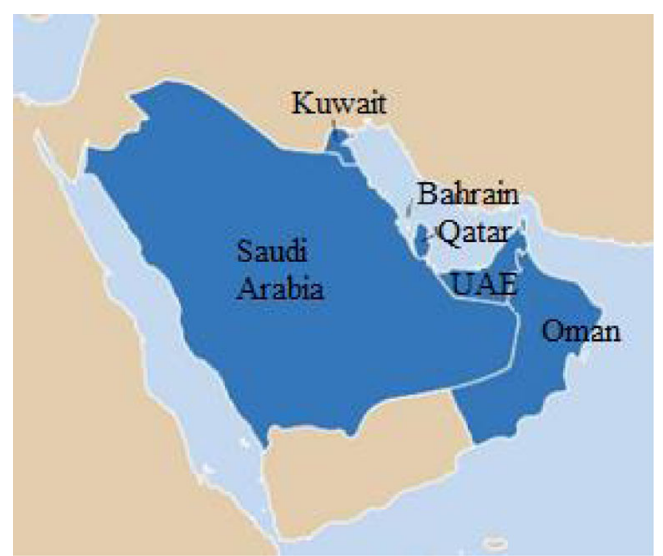

Fig. 1 Map of the GCC region

forecasting to reliable the electrical source at any extension for the building or any increasing in the future in the demand electrical power "2010 [3]". In another hand, with more than 1000 TWh at 2025 required in Arabian GULF, needing for reliable power plants is require which cannot depend on renewable energy power plants alone. To produce electricity, a power plant needs a source of heat to produce super steam out of water. The steam then turns a turbine that can be used to turn an electrical generator to produces electricity.

\section{Value the Electricity in Gulf Region}

GCC consumption growth was driven by the UAE and Oman, followed by Saudi Arabia. The fastest growing markets are, at the time of writing, those of the UAE and Qatar. Both countries witnessed average annual consumption growth rates of above 9 per percent over the first decade of the twenty-first century, compared with close to 8 per percent in Bahrain and Oman, and between 5 and 6 per percent in Saudi Arabia and Kuwait as showing in Fig. 2 "Laura El-Katiri-2011-[4]". The annual electricity

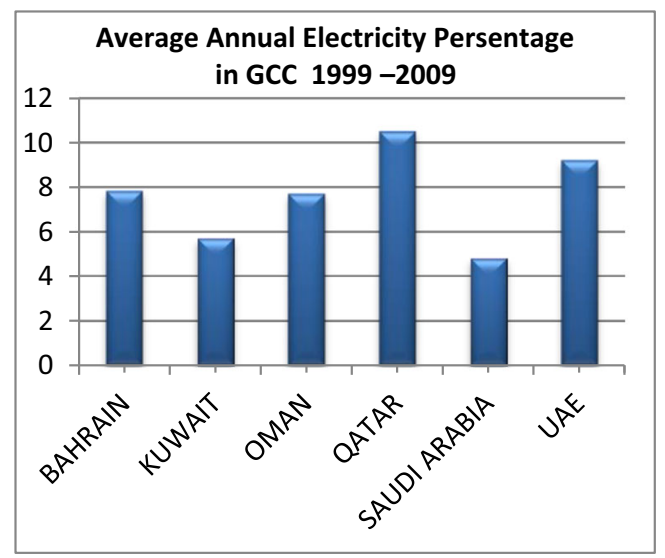

Fig. 2 Average growth in from the GCC, 1999-2009

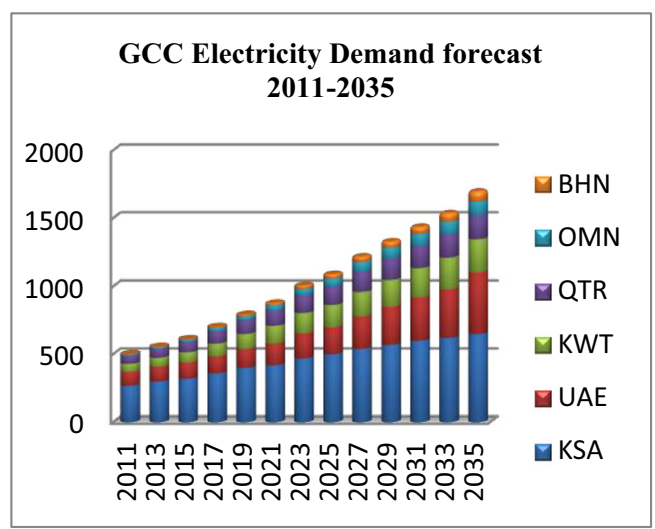

Fig. 3 Electrical demand forecast 2011-2035 (TWh)

demand in the GCC will increase from 467 TWh in 2011 to about 1400 TWh in 2030. Figure 3 discuss the GCC electrical demand forecasting to 2035 "Mycle Schneider, Antony Froggatt, Yurika Ayukawa-2014 [5]".

\section{Renewable Energy in GULF}

The value of the renewable energy in Gulf countries can be discussed with simple Pie charts. Figure 4 shows the values of renewable energy in Bahrain, it's found the value of solar energy is the higher percentage which $35 \%$ and the wind energy is the second by $30 \%$. For the renewable energy used in Qatar shows in Fig. 5, that discusses the solar energy is $40 \%$ and the Biofuel is the second by $30 \%$. Figure 6 shows the available from renewable energy in KSA, that shows the solar renewable energy by $35 \%$ and the Geothermal by $30 \%$. The renewable energy available in Oman depicts in Fig. 7, which show the high value available from solar by $40 \%$ and the second is the biofuel by $30 \%$. Figure 8 shows the available in UAE from the renewable energy the shows the higher value from the solar energy by $55 \%$ and the wind by $20 \%$.

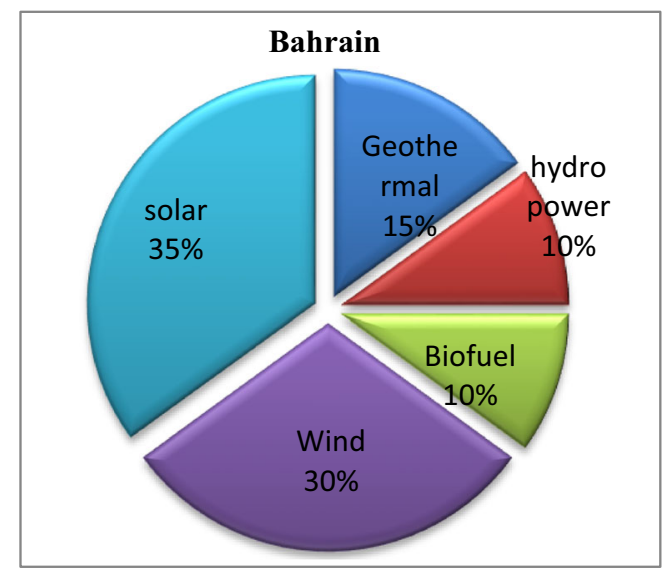

Fig. 4 Renewable energy percentage in Bahrain 


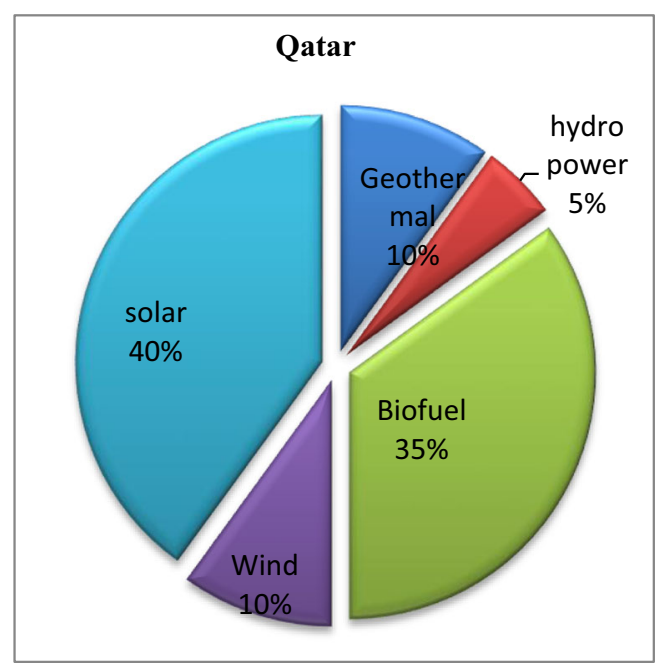

Fig. 5 Renewable energy percentage in Qatar

Figure 9 shows the renewable energy that's available from Kuwait, that shows the solar energy is the high value by $35 \%$ and the second is the wind energy by $30 \%$. "2015-[6]".

The Arab region's renewable energy potential is high, particularly for the wind and solar projects. But, the weather changes and high winter rainfall makes the utilization of solar energy in the winter period not suitable to rely on the full adoption, in the summer period and the presence of wind loaded with dust make the utilization of solar energy is disproportionate with the increase in the amount of demand for energy in the region. Where, to plan depend on the solar or wind energy.

\section{General Overview About NPP in World}

There are 31 countries in 2014 were operating reactors for nuclear fission for electrical energy. NPP generated 2,359

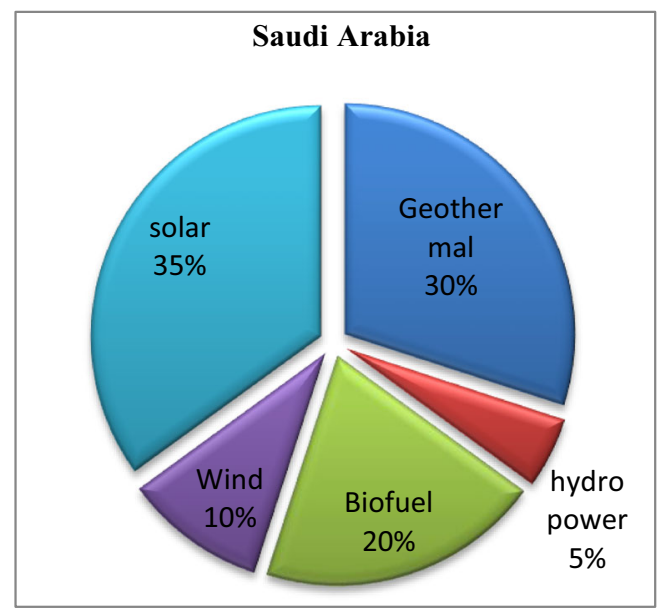

Fig. 6 Renewable energy percentage in KSA

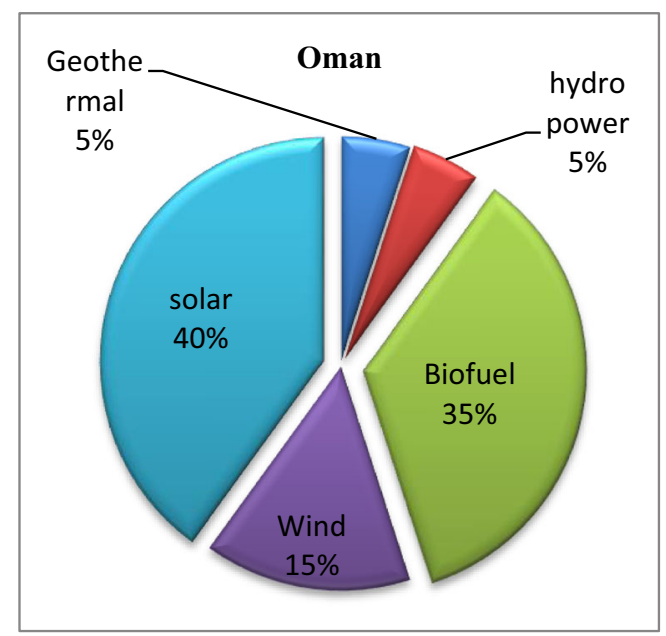

Fig. 7 Renewable energy percentage in Oman

net terawatt-hours (TWh or billion kilowatt-hours) of electricity in 2013, but still less than in 1999 and $11.3 \%$ below the historic peak nuclear generation in 2006. NPP for electricity declined in 13 countries, while in 16 countries it increased and remained stable in two. And six countries in the world generated their historic maximum in 2013. Figure 10 shows NPP for electricity generation in the World from 1990 to 2014 that's mention to maximum generation value is $2.66 \mathrm{TWh}$. Figure 11 shows annual nuclear power generation by country and historic maximum "2014-[5]".

\section{Construction Cost for NPP}

The NPP in service from more than 50 years ago, its forecasts for costs to extend in the future with high technology to the values from first NPP in the world that's from 1950 to 1960 , but for more save it has been consistently unreliable. This trend continued with the construction of second

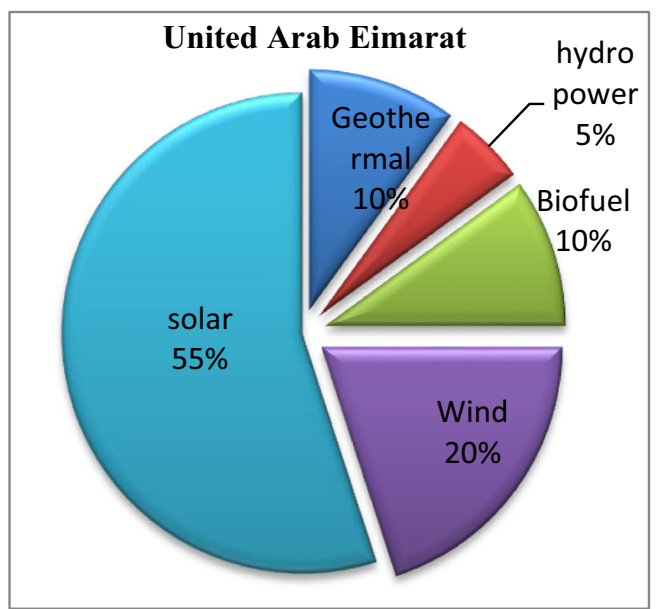

Fig. 8 Renewable energy percentage in UAE 


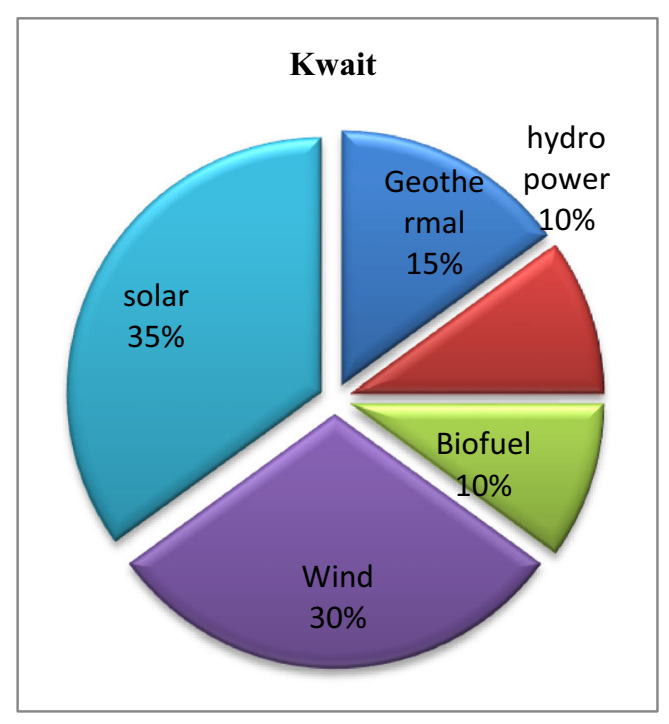

Fig. 9 Renewable energy percentage in Kuwait

generation operated in service in the 1970s, which make up the present nuclear fleet "2013-[7]". In the case of both solar and nuclear power plants, the primary components of the electricity costs are the capital costs of the installation. In the case of natural gas plants, depending on the cost of the gas, it could be either the fueling cost or the capital cost. Because domestic gas prices in Arabian GULF are so low, the capital cost is again the dominant element. Over time remains a work in progress research study, in nuclear power plant construction cost and time performance it's a large number of sizeable industrial projects. Cautious with ascribing all observable impacts to the internal economies or diseconomies of the reactor builder, reactor costs really did come down during the 1990s in many countries. As far as the subsequent cost fortunately, external influences can go either way. Disassembly of the reactor or insurance to malfunction or a problem with the reactor could affect agriculture or tourism to the country by the existing radiation. External factors such as increases in the price of steel, specialized labor and energy played a significant role. Not everything can be controlled. Only two thirds of the costs can be considered as firm at the time of signing the contract; the rest is variable. Fortunately, external influences can go either way " 2013-[8]".

\section{Analysis Cost for Construction}

Nuclear reactor capacity of a $1000 \mathrm{Mw}$ (this power equivalent to one million KWh which is $8.7 \mathrm{TWh}$ per year). Nuclear reactor does not work all time in year, but stops for the purpose of maintenance for almost two months. So, the actual production of 7.3 TWh per year and is calculated by dividing the annual Arabian GULF consumption (1000 TWh in year 2023) on the actual production of the reactor is one of the reactors needed by the total electricity demand of any 136.9 nuclear reactors, there are currently no nuclear power plant to generate electricity in the Arab world. The nuclear reactors are different rates depending on their specifications, including capacity and the exploited.

Jordanian and Russian sides signed an agreement provides for supplying Jordan with nuclear capability $1000 \mathrm{MW}$ each reactor for 60 years select ten billion dollars "2014-[9]". Figure 12 shows the total cost for construction nuclear power plant where found $60 \%$ is direct costs and 40\% indirect costs "John Moore -2013-[10]".
Fig. 10 Nuclear Generation in the world from 1990 to 2014

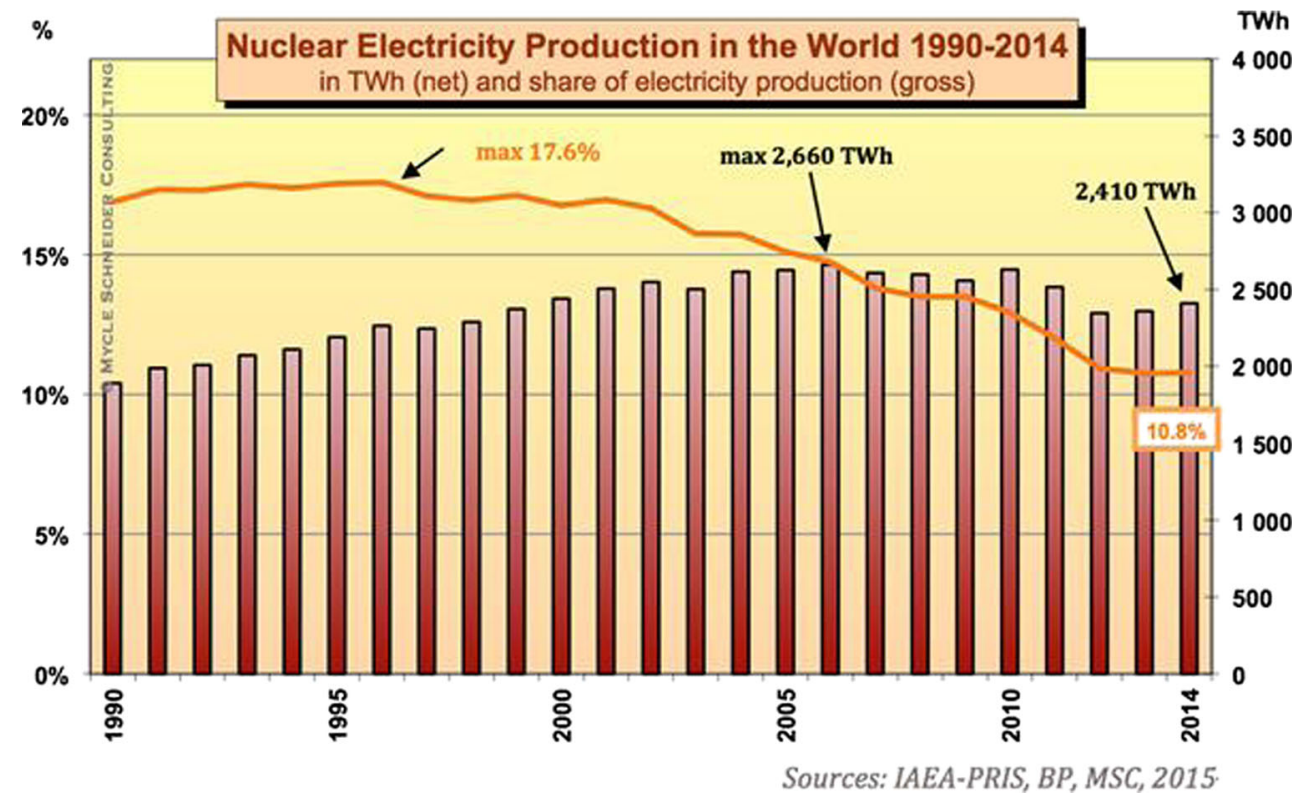




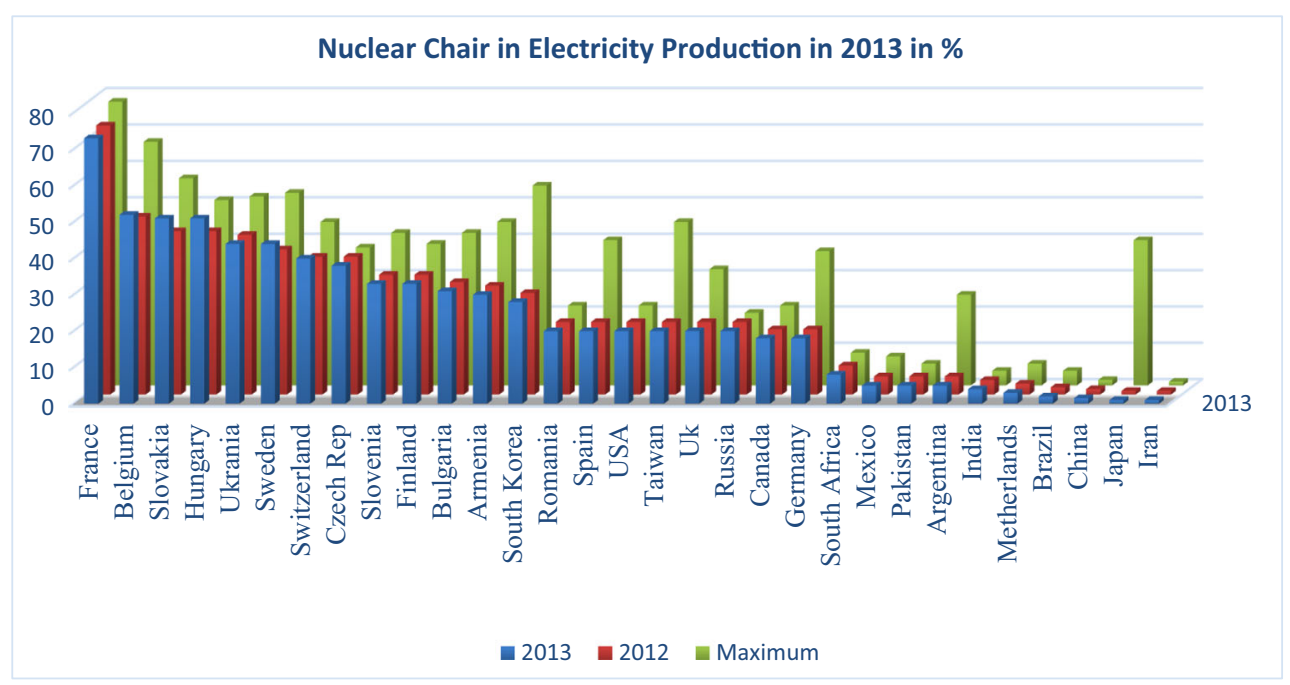

Fig. 11 The world countries value from nuclear electrical in 2013

\section{Operating Costs for NPP}

Nuclear plants require Uranium, although other materials may be used (See MOX fuel or Thorium). In 2005, prices on the world market for uranium averaged US $\$ 20 / \mathrm{lb}$ (US\$44.09/kg). On 2007-04-19, prices reached US $\$ 113 / \mathrm{lb}$ (US\$249.12/kg) [11]. The capital costs to construct the fuel or gas and oil electric generation is less than the cost for NPP, but the running cost for the uranium is very low at comparing with the fuel generation, but the outage from the waste uranium is require to high cost. So, it's important to treat this problem by allowances near to half of the cost is due to enrichment "2003-[12]". In the estimation economics of NPP, some costs for the management of radioactive to the disposal of this wastes by the separated. But, also after adding this costs to the NPP running costs,

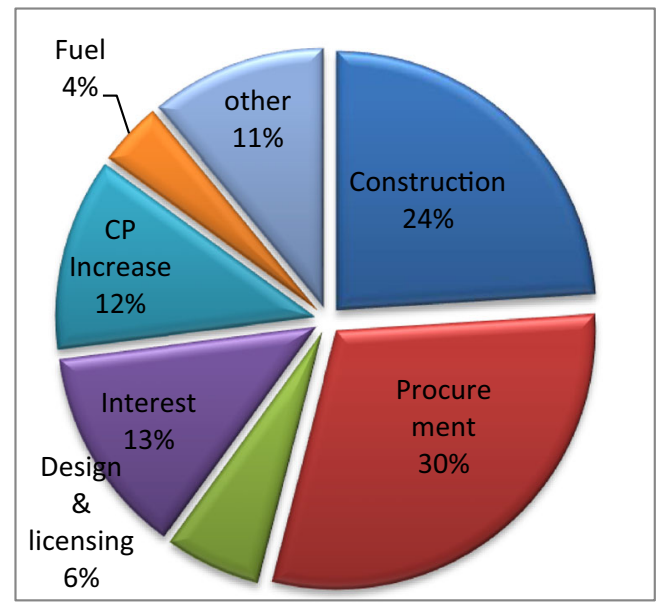

Fig. 12 Total cost for construction nuclear power plant the total costs of NPP are equalized approaching to quarter from combined gas substation and third of those for a coal plant. The US NPP Institute propose that for a coal plant costs are decreased to $14 \%$ by using NPP. In July 2015, the approx. US ( $20 \$$ to $50 \$$ ) cost to get $1 \mathrm{~kg}$ of uranium as UO2 reactor fuel (at current long-term uranium price) "2016-[13]".

\section{Operation of the NPP}

NPP generate the electricity by the same way that used with thermal generation power plants. The flaming fuel is used to generate the heat; that's used to produce the steam to spin turbines, which in turn generate electricity. The difference with NPP is that instead of using the flaming of the fossil fuels to generate the heat by use the nuclear fission to generate the heat. The fission in simple terms is the splitting of large atoms into smaller atoms; this process delivers large values of energy "2016-[14]". Figure 13 shows nuclear fission generates heat which typically uses fuel to produce heat to boil water that delivers the steam to spin a turbine.

\section{Uranium Fission in Nuclear Reactor}

The uranium 246 is used as the fuel for NPP. Most of the $99.3 \%$ from uranium is consist of a nucleus with 146 neutrons uncharged and 92 protons positive charged. Adding the number of neutrons and protons will create atoms having a total of 238 neutrons and protons which called atomic number atomic number, and refer to this nucleus as uranium238 , or just U-238. However, not all uranium atoms have 146 neutrons; $0.7 \%$ having 143 , which called U-235. 


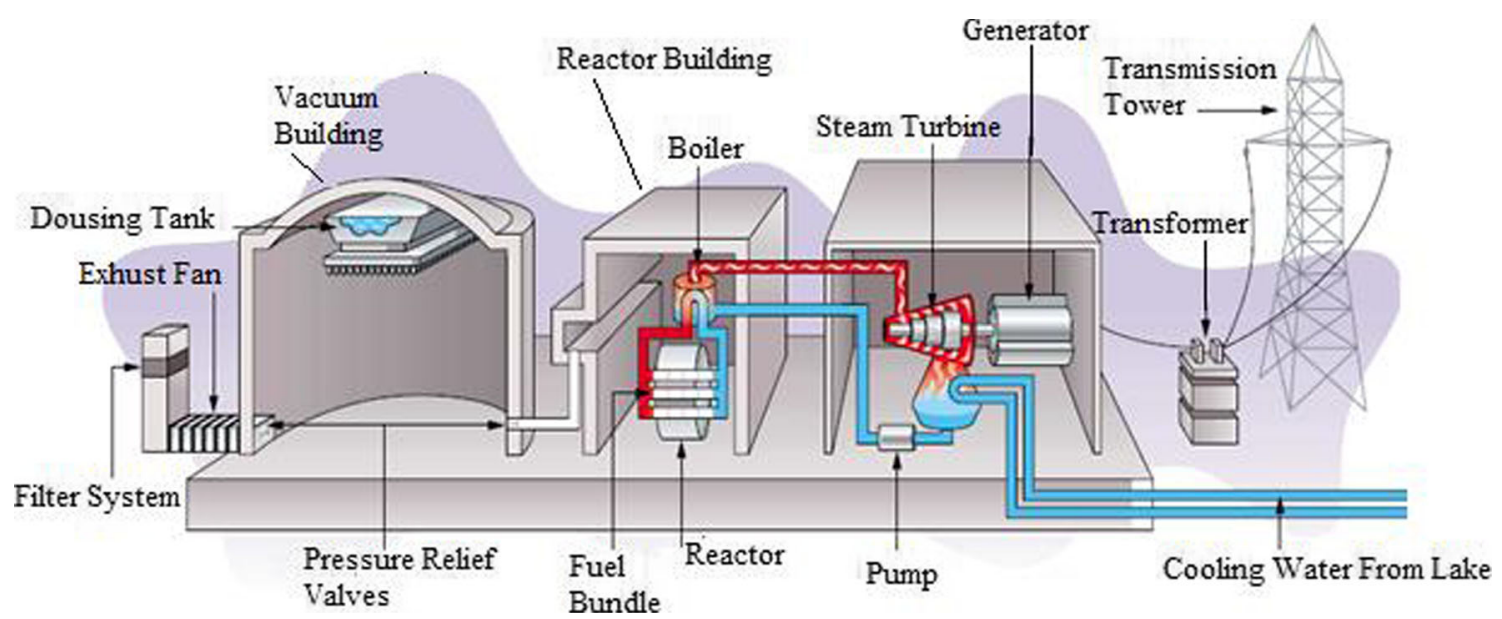

Fig. 13 Nuclear Reactor generates heat to operation the turbine

Although uranium 238 and 235 consider a type of the uranium but there are varying in characteristics. Where U235 automatically fissions, that creates two smaller nuclei and two to five neutrons that generate the heat energy. These fissions for U-235 is applied in the reactor, through this process is increase the numbers of U-235 from $0.7 \%$ to 3 to $4 \%$. At this process, the one neutron was used and three new neutrons produced. The three new neutrons are renewed by initiate the U-235 atoms fissions, this chain reaction of U-235 is shown in Fig. 14 [15]. In Eq. 1 discuss uranium fission with neutron.

$U_{92}^{235}+n_{0}^{1}=B a_{56}^{141}+K r_{36}^{92}+3 n_{0}^{1}$

\section{Safety Requirements}

The safety system is the main important at construct and designs the NPP, that's must be meet all requirements for safe the environment and the worker with accurate operation by allowing dependability for the system at all time for the operation in the future "2015-[16]". The safety in

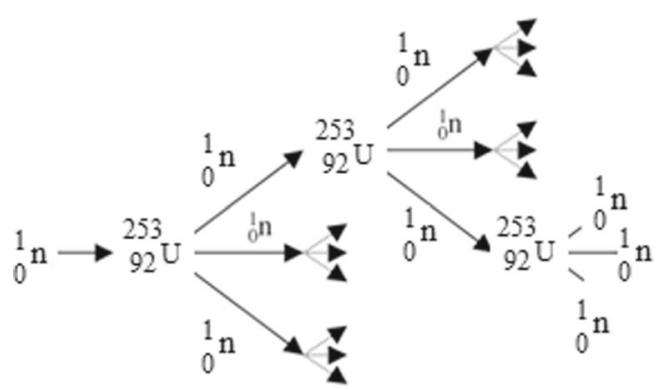

Fig. 14 Chain reaction uranium 235 fission
NPP requirements is direct by the objective and policy of the international safety rules. Technique and format of the safety requirements in NPP expedite their use for the corporation, in a harmonized manner, of a national supervisory structure. "IAEA-2014-[17]", "2015-[13]".

\section{Hydrogen Risk}

Hydrogen generated during accident conditions may pose a serious threat to water-cooled reactors. Once released into the containment atmosphere, hydrogen can form a combustible or explosive mixture with air [18]. Ignition of this flammable mixture will initiate a combustion process that may damage relevant safety systems and can even jeopardize the integrity of the containment wall. In the worst-case, the safety function of the containment can get lost "State of UFG-2012-[19]". The hydrogen risk assessment methodology of NRG consists of the following consecutive steps; Hydrogen can be generated and released to the reactor containment during a severe accident. Hydrogen combustion inside the containment or adjacent building may damage relevant safety systems and can jeopardize the integrity of the containment wall. CFD can be used to accurately predict the distribution of hydrogen in the containment as well as the combustion process and resulting pressure loads. In addition, CFD can predict the effectiveness of severe accident mitigation measures like sprays and re-combiners.

\section{Pressurized Thermal Shocks}

During emergency core coolant injection, a large amount of relatively cold water is suddenly introduced into the reactor vessel. 


\section{Thermal Fatigue}

Temperature oscillations in the coolant flow can induce thermal fatigue damage in reactor structures and components, affecting the reactor life time.

\section{Advantages and Dis-advantages of NPP}

\section{Advantage of NPP}

- $1 \mathrm{~kg}$ of fuel of uranium gives energy equivalent 3,000 tons of high grade coal.

- Fossil fuel reserves depleting at higher rate. Therefore, the cost of electricity production through coal and oil reserves increases per kilowatt hour compared to nuclear power plant, i.e, operational cost of nuclear plant is cheaper

- NPP require little space compared to thermal power plant for the same MW output. Thermal plants require lot of space for coal.

- Nuclear fuel is available in plenty amount all over the world.

- The output efficiency of nuclear plants is higher compared to thermal power plants.

- Nuclear plants always operate as base load plants. Therefore, plant availability factor and load factor of the plant is quite high [20].

\section{Disadvantage of Nuclear Power Plant}

- Radioactive wastage and storage problem.

- It requires large capital cost.

- The nuclear reactors will work only as long as uranium is available.

- It requires large mass of water for cooling purpose.

- Therefore, the plant should be located near sea or river.

- It requires large area around the plant to be isolated from living.

- During shutdown of the reactor, decay heat is produced from the reactor due to the fission daughter product.

- Building of a new nuclear power generation plant is in the range of 20 to 30 years.

- Mining and transportation is costly and is dangerous " $\mathrm{H}$. N. Mu, J. W. Liu and M. C. Lu-IEEE-2016-[21]".

\section{Planning for NPP in the Future}

Renewable like solar or wind power plants is very important to save a considerable amount of oil. But, they are not secure option for feeding basic loads. Nuclear power plants are the best option to feed basic loads. Uranium is available element in many places on earth and now feeding about 1000 nuclear power plants around the world. As discussed, the costs of both nuclear and solar technologies go up sharply with the discount rate, while gas is relatively stable. However, nuclear costs are more sensitive because of the long construction period over which the expenditures are incurred. While we have assumed the same discount rate for all technologies, there are good reasons to use of a higher discount rate specifically for nuclear power plants. Several economists have argued for such higher discount rates because nuclear projects are financially more risk "2003-[22]", "2012—[23]" and "IEEE-2006-[24]".

There are more studies working to both support a nuclear future such as the push for clean energy and against it like costs. Unless, of course, emerging technologies come to the rescue. One proposed solution is to build small, modular reactors "IEE-2016-[25]". The demand power at 2035 is $1700 \mathrm{TWh}$, by starting to construct nuclear reactors with plan to 2035 reach to near $35 \%$ from total demand power by NPP, its will limit from natural gas and oil power plant. And will face the future problem from decreasing in the fossil fuel. this suggestion required to 81 nuclear reactors, and its can reach to this target by dividing the projects to start by 5 Reactors/year, Capital cost to construct one reactor is 5 billion by operation capacity $1000 \mathrm{MW}$.

\section{Conclusion}

There are many studies that evaluate the construction cost of electricity for alternative generating technologies. So, all countries search about renewable energy. The demand power in GULF countries is increases very fast, but the renewable sources of energy, such as wind or solar power plants are low efficiency and depend on the environmental stability. In GULF countries, the using of alternative energy is still limited as demonstration projects have shown high cost compared with conventional power generation. By examined the economic prospects for nuclear power in Arabian Gulf it has been found that they are not favorable in comparison with natural gas, even if the currently low domestic natural gas prices in Arabian Gulf were to rise substantially. But nuclear reactor capacity of a $1000 \mathrm{MW}$ this power equivalent to one million $\mathrm{KWh}$ which is $8.7 \mathrm{TWh}$ per year and reactor can be work for 60 years by cost 5 billion dollars, but the diversity of energy sources dependence is required where the future is not guaranteed for nonrenewable energy compared with renewable energy such as nuclear power plant. 


\section{References}

1. Toth FL, Rogner H-H (2006) Oil and nuclear power: past, present, and future. Energy Econ 28:1-25. Published by Elsevier B.V. All rights reserved. https://doi.org/10.1016/j.eneco.2005.03.004

2. Shaahid SM, Al-Hadhrami LM, Rahman MK (2013) Economic feasibility of development of wind power plants in coastal locations of Saudi Arabia- a review. Renew Sustain Energy Rev Elsevier Renew Sustain Energy Rev 19:589-597. https://doi.org/10. 1016/j.rser.2012.11.058

3. Chaturvedi DK, Premdayal SA, Chandiok A (2010) Short-term load forecasting using soft computing techniques. Int J Commun Netw Syst Sci 3:273-279. https://doi.org/10.4236/ijens.2010.33035

4. El-Katiri L (2011) Opportunities and challenges of GCC electricity market cooperation. Oxford Institute for Energy Studies, (Registered Charity, No. 286084). ISSBN—978-1-907555-29-9

5. Schneider M, Froggatt A, Ayukawa Y, Burnie S, Piria R, Thomas S, Hazemann J (2014) The world nuclear industry status report 201. Paris, London, Washington, D.C.

6. Jerath KS, Millerjothi NK, Karthiyayini S, Sharma A (2015) Forecast analysis of potential and availability in renewable energy. Int J Environ Sci Dev. https://doi.org/10.7763/IJESD.2015.V6.615

7. Mu HN, Liu JW, Lu MC, Lu C (2016) Reliability analysis method of phased-mission nuclear power equipment based on goal oriented methodology. In: Industrial engineering and engineering management (IEEM). IEEE

8. Mancini M, Locatelli G, Sainati T (2015) The divergence between actual and estimated costs in large industrial and infrastructure projects: is nuclear special. In: Nuclear new build: insights into financing and project management

9. Menzel F, Sabundjian G, Cavalieri T, Stecher LC (2015) Calculating the environmental cost of the nuclear power plants Angra 1, 2 and 3 using the program SIMPACTS. In: 2015 5th international youth conference on energy (IYCE). IEEE. https://doi.org/10.1109/IYCE.2015.7180792

10. Moore J (2013) NPP construction activities. Nuclear Power Division. International Atomic Energy Agency (IAEA)

11. What's behind the red-hot uranium boom-http://money.cnn.com/ 2007/04/19/markets/uranium/index.htm

12. Sims REH, Rogner H-H, Gregory K (2003) Carbon emission and mitigation cost comparisons between fossil fuel, nuclear and renewable energy resources for electricity generation. Energy Policy 31:1315-1326. PII: S0301-4215(02)00192-1

13. Rasmussen NC (1975) Nuclear power: Rasmussen on reactor safety: how nuclear power reactor risks are quantified; and nuclear sabotage, theft, shipping, and waste disposal risks put in perspective. IEEE Spectr 12(8):46-57. https://doi.org/10.1109/MSPEC. 1975.6368923

14. Giraldo JS, Gotham DJ, Nderitu DG, Preckel PV, Mize DJ (2012) Fundamentals of nuclear power. State Utility Forecasting Group

15. Wilson NE (1955) Operation of a nuclear power plant on an integrated electric system. Electr Eng 74(11). IEEE. https://doi.org/10.1109/EE.1955.6439637

16. Oedewald P, Gotcheva N, Wahlstrm M, Gotcheva N, Wahlstrm M (2015) Safety culture and organizational resilience in the nuclear industry throughout the different lifecycle phases. VTT Technology, Espoo. ISBN 978-951-38-8306-5

17. International Atomic Energy Agency (2014) IAEA safety classification of structures, systems and components in nuclear power plants. ISBN 978-92-0-115413-2

18. Sadhankar RR, Li J, Li H (2006) Future hydrogen production using nuclear reactors. In: EIC climate change technology. IEEE. ISBN: 1-4244-0218-2

19. Stone GC, Chan C, Sedding HG (2016) On-line partial discharge measurement in hydrogen-cooled generators. In: IEEE electrical insulation conference (EIC). IEEE. ISBN: 978-1-46738706-4

20. Pearce JM (2012) Limitations of nuclear power as a sustainable energy source. Sustainability 4:1173-1187. https://doi.org/10.3390/su4061173

21. Banu M R, Sowghandhi, Venugopal P (2013) A study on Charanka solar park and Kudankulam nuclear power plant in India. Int $\mathrm{J}$ Emerg Sci Eng (IJESE). ISSN: 2319-6378

22. Beckjord ES (2003) The future of nuclear power an interdisciplinary MIT study. Massachusetts Institute of Technology. ISBN 0-615-12420

23. Ahearne JF, Carr AV Jr, Feiveson HA, Ingersoll D, Klein AC, Maloney S, Oelrich I, Squassoni S, Wolfson R (2012) The future of nuclear power in the United States. In: 2012 by the Federation of American Scientists and Washington and Lee University. All rights reserved. Printed in the United States of America, ISBN 978-1-938187-00-1

24. Ahmad A, Ramana MV (2014) Too costly to matter: economics of nuclear power for KSA. Energy J. https://doi.org/10.1016/j.energy.2014.03.064

25. Alam SB, Kabir HMD, Sazzad ABMR, Redwan K, Aziz I, Chowdhury IK, Matin MA (2010) Can gen-4 nuclear power and reactor technology be safe and reliable future energy for developing countries? In: IEEE international conference on power and energy (PECon). https://doi.org/10.1109/PECON.2010.5697567 